\title{
The Effects of Marine Simulators on Training
}

\author{
Rashed Al Shahin \\ Kuwait
}

\begin{abstract}
Simulators have increased its usefulness in marine training over the years. Literature cites its many advantages which should ultimately lead to the increase in sea safety. However, more remarked than the discomfort felt by the trainee due to the lack of human interaction, simulation-training was noted to be costly and does not provide a clear indication of its value in organizations as no information supports this. A comparison of other technology which could be used for training is shown to provide an insight to the probable technology-based alternatives for simulators. In the search for the effects of marine-simulators on training, a few literature indicated its effects. Studies indeed specify favorable effects of simulators to training. However, no definite or quantifiable explanations were shown to relate training to its ultimate purpose of improving sea safety. Studies reviewed explored the effects of training to teamwork and the effects of training on the cognitive abilities of trainees. The Lewin study on the effects of CRM training indicated positive outcomes but was unclear about the link of training effectiveness with safety. The perception study revealed significant results in the perceived change of attitude, knowledge, and skills. The other study was on determining the physiological response related to cognitive activities which revealed that a rise in frequency values was observed during problemsolving in navigational situations. Simulator systems in training institutions were examined to provide a glimpse of how training may be made more effective.
\end{abstract}

Keywords: marine-simulators, simulator-training

\section{INTRODUCTION}

Simulation has become a common feature of maritime training for decades (Wang, Cheng, Ma, Song, Liu, \& Wang, par. 1; US GAO, 2013) as quality immersion training does not seem to be sufficiently provided only by training centers (Judson, par. 2). For marine simulation training, ship handling or ship bridge simulators are ever more accepted as a possibly helpful training medium for deck officers (Hammell, Gynther \& Pittsley, 4). Simulation-training develops hands-on and fault-treat abilities (Wang et al., par. 1). Since hydrodynamic data and geographical database are features of marine-simulator programs, simulators enable performance required for maritime professionals (Salman, 17). To determine the usefulness of simulation-based training against live training, Marine officials had deliberated over a few factors. These factors included the training mission or objective, the safety of the service members, training frequency, availability of training time, need for replication of scenarios, availability of training devices, and the extent of realism (US GAO, 9). As a result, the Marine Corps has recognized that simulation-based training complements live training (US GAO, 1). The rationale for the use of simulation is the improvement of the quality of training and the position of readiness and the capacity for saving costs, a valuable but subordinate factor (US GAO, $10)$.
Moreover, International Maritime Organization standards, aside from the increasing number of marine industries worldwide, stress the use of simulators during training (Salman, 69; Lewin, 15). The organization upholds its effects in improving competency and facilitating certification. In the Marines, simulators have been used to train service members in various tasks which could not be instructed live considering the risks, both in aviation and ground communities. Although efforts to improve the interoperability of these training methods could be noted in both the live and simulation-based training programs, broader applications of simulators and simulations in training could also be observed. Its increased use has resulted in the development of some devices such as in aircrafts, which have been used for more than fifty years. Ground communities only began using simulators in the 1980s and focused more on live training (US GAO, 5). Technological developments have paved the way for more simulation-based training especially for ground forces (US GAO, 2). The Indoor Simulated Marksmanship Trainer, for example, has provided the opportunity to improve the capability to train in marksmanship, both in basic and advanced levels (US GAO, 7). This simulator can also be reconfigured to imitate various weaponry. Another simulator is the Combined Arms Command and Control Trainer Upgrade System which provides training for rehearsing tactics, decision making, procedures, and techniques in a realistic set-up (US 
GAO, 7). In 2013, the Marine Corps was developing its Live, Virtual, and Constructive Training Environment to enable the assimilation of live and simulation-based training mechanisms (UA GAO, 8). The eventual outcome is the creation of a common environment so that units can impeccably act together, simulating simultaneous physical presence. Overall, the new technology contributed to the refinement of skills of service members due to the concentrated and repetitive training. But then, new equipment has also made it difficult to assess the evaluation of training outcomes because of the reduced knowledge of the technology; thus, impelling a need for increased familiarization of technological features (Stan, 4521). So far, the use of simulation training has not provided performance and cost indicators or metrics to optimize training objectives. Performance metrics are identified as an effective management practice to determine the impact of training. Establishing the impact of training can improve outcomes and detect performance gaps. Additionally, the allocation of resources could be better determined to achieve the desired changes in the trainees' knowledge and competencies. Without this information, the ability to make better quality decisions about the optimal training mix and investment decisions is hindered. Realizing this since, the service has initiated research to address this concern though hampered by the pace of operations in the Middle East and the need to conduct training and prepare the forces for deployment (US GAO, 12). Obstacles in gathering the performance metrics of simulationbased training arise from the subjectivity of training tasks and the complexity of developing specific and quantifiable indicators for different devices.

\section{Benefits and limitations of simulators in training}

The value of simulator training can be observed innately and practically. Generally, as one of the training methods, simulations allow the trainees to make decisions resulting in outcomes that mirror what would occur if the trainee were on the job as simulators replicate the environment use for actual tasks. The impact of the decisions made in an artificial, risk-free environment teaches skills inclusive of production, process, management, and interpersonal aptitudes (Noe, Hollenbeck, Gerhart \& Wright, 287; Noe, 270). Stan (4522) cited that the "artificial experience" enhances professional judgment and offers the trainee manifold ways of tackling problems particularly those which requiring the management of risk and crisis. Simulation-training does not just contribute to the trainee's efficiency and experience as confidence in the job-situation is also promoted (Stan, 4522).
Training concepts and principles identified some reasons why simulations can be effective. Noe (2010) cited these reasons. First, trainees can use them on their desktop computers, reducing the need to travel to a main training area. Second, they get trainees involved in learning, and they are emotionally engaging. As a result, this increases the trainee's willingness to practice, promotes retention, and improves their skills. Third, they provide a consistent message of what needs to be learned. Trainees can work at their own pace. They can also combine more situations or problems the trainee might encounter.Goldberg (2013, par. 2) pinpointed that typical and atypical scenarios in simulations could broaden the trainee's experience. Fourth, simulations can safely put employees in situations that would be dangerous in the real world. Fifth, training time is shorter, thus, resulting in higher returns on investment. Salman (69) added to this list of advantages that simulators can be used in spite of weather conditions. Instructors can also stop training settings at any time. Still, another benefit is that training scenarios can be replayed and reviewed as often. Lastly, the learning environment is safe. Salman (70) expected that simulation training for the dredging division of the Iraqi fleet will be able to solve the shortage of experiential learning of entry-level officers.

Simulation-based training is generally considered by Marine Corps officials as more efficient than live training (US GAO, 2). Simulations can improve safety operations resulting in less accidents, thus saving funds, and in turn allow the provision of more training opportunities (Cross cited in Goldberg, par. 7; US GAO, 2). Live training is complemented, and basic skills are rehearsed more efficiently. While performance in live training is improved, cost savings are also enabled by the reduction of training sites or need for training land and training time, increase in safety and decrease in the wear and tear of equipment, reduction of the operating tempo costs as use of training ammunition is lessened. Moreover, a broad assortment of conditions can be duplicated which allows facilitation of mastery. Trainees also receive immediate feedback on their performance.

On the other hand, Noe (2010) also pointed out certain shortcomings of simulations. Primarily, development costs limit the use of simulations (Goldberg, par. 2). This is an expensive training method, and the effect of the use of marine simulators has been obscurely quantified due to numerous safety initiatives. Goldberg (par. 4) argued that simulator training has the potential for saving one's life, which makes its cost worthwhile based on this principle alone. 
However, he posited there is no basis to compare other safety initiatives which may be lower in cost than how simulator training can be used for this purpose. One more issue raised was that implementation decisions were deemed to be more emotional than rational. There is a need to exhibit that simulator training is indeed efficient by decreasing accident-related costs or performance issues (Goldberg, par. 4).

Supporting Goldberg's (2013) claims was a study by Professor Cross of the Netherland's Maritime Willem Barentsz (MIWB). Although the highlights of the study focus on the cost of simulation training, particular features of this study provide insight into the effects of marine simulators in training. What is salient for this paper is that there were accidents which could be attributed to training limitations and the level of competencies improved through simulator training (Cross cited in Goldberg, par. 10). The MIWB study indicated that 35 percent of accidents were attributed to improper training. On an even higher ratio, 46 percent of accidents were caused by bad habits, attributed to procedural training. An overall 81 percent was attributed to the lack of sufficient training. Other studies cited in this research supported that 63 to 70 percent of the accidents evaluated could have been prevented if personnel were better trained. Kim (81) supported this claim that the limited knowledge about maritime equipment contributed to most of the maritime casualties. Another significant issue provides insight to the applicability of simulator training. Since a simulator could not teach or allow the practice of all competencies required for safe operations, the level of competencies which can be taught has to be determined (Cross cited in Goldberg, par. 20). Findings in this area revealed about 58 percent of the competencies were teachable. When a competency improvement was conducted using simulator training, outcomes for the experienced and inexperienced groups of mariners showed improved competencies. An improvement of 45 percent in the average performance was recorded. To satisfy the ultimate objective of the MIWB study, a further analysis of these results indicated that simulator training contributed to a 14 percent reduction of accidents.
Goldberg (par. 30) concluded that simulation training as both a worthwhile cost-saving measure and safety improvement measure. Nevertheless, costs have been continuously decreasing over time. Meanwhile, another disadvantage is that trainees may not find a sufficient level of comfort in learning situations as there is little or no human contact.

There are a variety of technology-based training methods used by other sectors which the Marines can also use. The nature and use of simulators indicate the degree to which they are similar to the equipment and situations the trainee will encounter on the job (Noe, 271). Also, simulators should necessarily respond exactly as the equipment would under the conditions and response given by the trainee, which make simulator more expensive to develop and need constant updating as new information about the work environment is obtained (Noe, et al., 287). To further justify its use in training and provide an overview of the benefits and limitations of simulations, Table 1 presents a comparison of technology-based training methods.

The comparison reveals an all favorable view for simulations, and virtual reality as all parameters of comparison mostly indicated 'yes' or 'high' comments. However, since the methods were also technologically-based, most of the learning outcome aspects showed favorable results. Among the aspects of comparison, learning outcomes are most significant to the goals of training, while learning environment, transfer of training, and cost may be considered supplementary to the learning outcomes. Effectives, according to Noe (334) was determined based on the characteristics of a positive learning environment and learner control, sharing, and linking are built into these methods. The other factors may be subject to the preference of the organization and the availability of its resources. If cost and observation and interaction with others are significant requirements of the organization, the choice of simulations may be doubted. Nevertheless, simulations in the table below suggest a strong preference for simulations among the technology-based training methods.

Table 1. Comparison of technology-based training methods

\begin{tabular}{|l|l|l|l|l|l|l|l|l|l|}
\hline & $\begin{array}{l}\text { Simulations } \\
\text { and virtual } \\
\text { reality }\end{array}$ & $\begin{array}{l}\text { Computer- } \\
\text { based } \\
\text { training }\end{array}$ & $\begin{array}{l}\text { CD- } \\
\text { ROM }\end{array}$ & Internet & Intranet & $\begin{array}{l}\text { E- } \\
\text { learning }\end{array}$ & $\begin{array}{l}\text { Distance } \\
\text { Learning }\end{array}$ & $\begin{array}{l}\text { Intelligent } \\
\text { Tutoring }\end{array}$ \\
\hline Learning Outcome & Yes & Yes & Yes & Yes & Yes & Yes & Yes & Yes \\
\hline Verbal Information & Yes & Yes & Yes & Yes & Yes & Yes & Yes & Yes \\
\hline Intellectual Skills & Yes & Yes & Yes & Yes & Yes & Yes & Yes & Yes \\
\hline $\begin{array}{l}\text { Cognitive } \\
\text { Strategies }\end{array}$ & Yes & Yes & Yes & Yes & Yes & Yes & Yes & Yes \\
\hline Attitudes & Yes & Yes & No & No & No & No & No & No & Yes \\
\hline Motor Skills & Yes &
\end{tabular}




\begin{tabular}{|c|c|c|c|c|c|c|c|c|}
\hline \multicolumn{9}{|c|}{ Learning Environment } \\
\hline Clear Objective & High & Medium & High & High & High & High & Medium & High \\
\hline Practice & High & Medium & High & Medium & Medium & High & Low & High \\
\hline Meaningfulness & High & Medium & High & High & High & High & Medium & High \\
\hline Feedback & High & Medium & High & Medium & Medium & High & Low & High \\
\hline $\begin{array}{lr}\begin{array}{l}\text { Observation } \\
\text { interaction } \\
\text { others }\end{array} & \text { with } \\
\end{array}$ & Low & Low & High & Medium & Medium & High & Low & Low \\
\hline $\begin{array}{l}\text { Transfer } \\
\text { training }\end{array}$ & High & Medium & High & Medium & Medium & High & Low & High \\
\hline \multicolumn{9}{|l|}{ Cost } \\
\hline Development & High & High & High & High & High & High & Medium & High \\
\hline Administrative & Low & Low & Low & Low & Low & Low & Low & Low \\
\hline Effectiveness & High & Medium & High & $?$ & $?$ & High & Medium & $?$ \\
\hline
\end{tabular}

Source: Noe (2010). Noe indicated "?" in a few of the methods.

\section{Effects of simulation-based training}

An early evaluation of the effects of marine-simulators was reported in 1985 by the US Department of Transportation, a joint effort by the Maritime Administration and Coast Guard units. A prototype simulator-based training program including a ship bridge/ ship handling simulator was assessed on the effects to twelve U.S. pilots. The goal of the study was to gauge the effectiveness of this method of training, the specific skills trained by the simulator and the impact of pilot experience on its uses from the exercise (Hammell, Gynther \& Pittsley, 4). The endeavor was inspired by the success of simulator training programs in Europe. The experimental training program targeted three skill areas: advanced instrumentation, emergency ship handling, and decision making. The data obtained from the participants included objective and subjective measures. Pre-test and post-test of ship handling performances were used as objective measures; while the pilots' opinions were obtained through a questionnaire.

Hammel, Gynther and Pittsley (1985) arrived at several conclusions which could have been the basis of the more current evaluative studies and the development of simulation-based training programs for the Department. One of the significant conclusions arrived at indicated that not all forms of simulator training are highly effective.Another conclusion was that any level of task experience, whether apprentices, less experienced, but qualified, or experienced pilots can gain from simulator training. Moreover, to get the most out of the learning outcomes, the types of training must be suitable to the level of experiences.The class sizes in this program comprised of four to five trainees. On hindsight, the benefit of simulation-training may be compounded by the interaction of the varying levels of experiences of the trainees. Thus, the interaction of trainees' experiences in a class may be a confounding variable and effectiveness of the simulator alone may not be exclusively concluded. It was also recognized ideal to have a mix of the levels of experiences in the same class undertaking the training. Still another conclusion made was that the port used for simulation did not have to be an actual port, but it should present challenges that may be found in the trainees' own ports. Lastly, a structured approach was useful in identifying the specific type of training which was derived from a listing of the specific skills of interest benchmarked from the European study. The areas for training were categorized as "Greatest Interest," "Moderate Interest," and "Weak Interest." Figure 1 show the classification of skills of interest for the marinesimulator training in this study. 


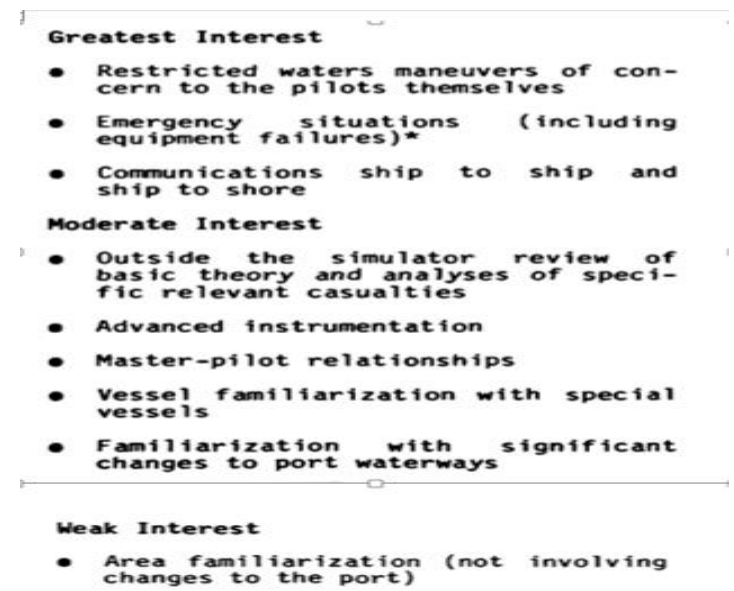

Figure 1. Classification of areas of training based on interest in the Hammel, Gynther and Pittsley

The Advanced Instrumentation training module (Module 1) evaluation provided six performance measures. These included maneuvering a vessel around a constant radius turn, actual rate-of-turn maintained compared with the ideal rate-of-return, number of rudder orders, number of course orders, minimum distance to channel boundary, and channel excursion. Four out of six of these measures, inclusive of the primary and secondary performance measures, yielded significant results. Overall, the Advanced Instrumentation simulation-training was concluded to be effective as majority of the measures showed significant results.

While a comparative performance was conducted between the pilots with limited experience and extensive experience, the results were expected to have a more substantial improvement for more experienced pilots in Module 1 as the depth of experience would have equipped the pilots more knowledge and skills. Nevertheless, their improvement confirmed that training effectiveness is regardless of the level of experience of the trainees. In Module II, Emergency Ship handling, three of the four performance measures indicated significant results. Course correction and number of rudder orders did not yield significant results; while the minimum distance to channel boundary, the number of course orders, and a number of engine orders significantly improved. Meanwhile, there was no significant difference between the performances of the limited and extensive experience groups.

A summary of these findings using t-test and Binomial-test were statistically evidenced as shown in Appendices 1 and 2. Pilots' perceptions of the training indicated the training could be beneficial and effective [italics mine] (Hammel, Gynther and Pittsley, viii). Perceptions on the benefits and effectiveness of the respondents are deemed uncertain. Since the opinions of the participants were gathered immediately after the training, their learning had remained to be proven at that point. Participants also viewed the importance of a high fidelity simulator. The conditions of the training pertaining to class size and its mix among others were also supported by the participants. On the other hand, they remarked that the training session was too short and limited to a few practice runs. The experimental study was conducted for one week.

A later study by the US Coast Guard in 1994 indicated that there was no sufficient evidence to support that simulators have improved seafarer performance (USCG cited in Salman, 48). However, the use of simulators over time has shown a satisfactory experience in producing the levels of competency. A need for further research was recommended. Salman (51) also discussed a few studies which showed that simulator training can replace sea service. The TNO/Marine Safety International (1994) study suggested that 40 hours of simulator time can replace 30 days of sea time. However, this can only be applied when the performance level is 50 percent of the level of performance after board ship training. But the Nautical Institute (1994, cited in Salman, 51) cited that simulation-training time should be restricted to one week for one month at sea. Meanwhile, reduction systems were observed in Norway, India, Hong Kong, and USA to name a few countries (Salman, 51). Since literature indicates a dearth of evidence to prove the effects of simulation-training to performance, a recent study in 2015 by Lewin showed a literature review of the effectiveness of training. Training in the studies was inclusive of simulation but was not exclusive to this type of training method. Lewin (49) specified that training effectiveness was determined against the length of training and the trainee's motivation, knowledge, skills, and abilities and significantly determined by the transfer of competencies to the trainees. In 
Lewin's review, a study cited 58 articles on Crew Resource Management (CRM) training for flight crews including the military where training resulted in favorable outcomes, better learning, and positive attitudes in the cockpit (3). Criteria for effectiveness were established as human reliability and safety performance $(4 \& 6)$. Furthermore, the CRM training indicated a positive impact on safety as a reduction of errors resulted, but results were inconclusive. On the one hand, he cited a scarcity of evidence on the effectiveness of training on safety in the maritime industry. Lewin's study aimed to address this gap between the effectiveness of training on maritime safety. Kirkpatrick's typology of evaluating training effectiveness from literature, as this was regarded a useful method to evaluate the success of training programs. In another study, Kumar, Anand and Punya (2) also relied on the use of Kirkpatrick's four-level approach to evaluating the effectiveness of training. Lewin's research findings revealed that of the eight literature found covering the effectiveness of training varied in high-reliability while shipping companies were only required to observe at minimum mandatory requirements (Lewin, 46). Additionally, teamwork on the bridge can be enhanced by CRM since the complexity of the technical environment requires cooperation and coordination. However, this desired scenario is limited to ships with a low turnover rate. CRM also improves situational awareness (SA) and teach the ability to handle peculiar situations. A lack of SA results in more accidents (Lewin, 48). This study concluded with an ambiguously link between CRM training and safety. This conclusion was supported with the recognition of the complex interaction of technology and personnel. Communication among the members of the ship's crew was suggested to be emphasized since this appeared to be a significant factor in the occurrence of accidents. Meantime for with ships with smaller crews, standard requirements for training must be ensured (Lewin, 60).

Although Lewin pointed to the rate of sea accidents from 1973 to 2003 to illustrate the need to emphasize the usefulness of simulation-training, there was no discussion or speculation even that the declining trend in the number of accidents at sea may have been brought about by the effects of training. Figure 2 shows the data on the loss rate of ships due to accidents during the more than two decades included in the data below cited in this study. On the one hand, STWC mandate was noted to require simulation training in 2012. As such, the decline in loss rate of ships may not attribute to the required simulation-training. Data between 2003 and 2012 must be further examined to support this.

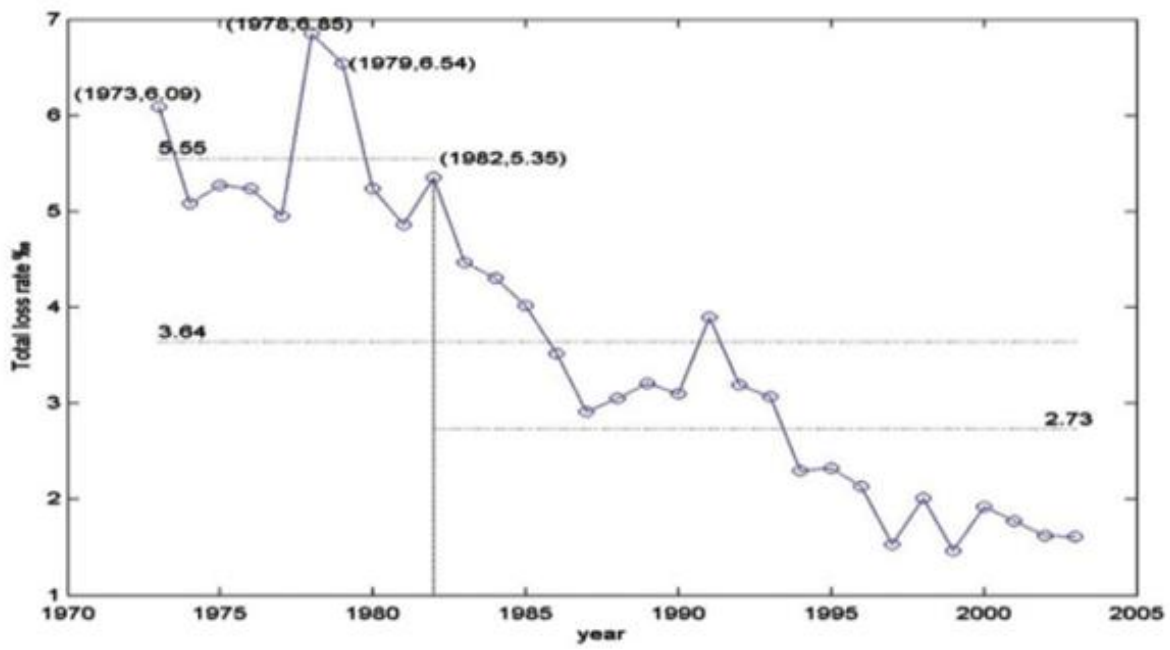

Figure 2.Total loss rate of ships between 1970 and 2003.

The study by Kumar, Anand and Punya (2015) was based on the trainees' perception of the effectiveness of learning from simulation-training based on Kirkpatrick's framework that learning takes place when attitudes change. It is assumed that attitudes in this study is operationally defined to describe the perceptions of the study participants. These perceptions can be examined in Table 2 where the inferences or decisions of the researchers were indicated. The research concluded that a perceived change in the knowledge and skills of the students was observed by the respondents themselves. Furthermore, simulation-training enhanced the levels of confidence of the students. This supports the claims of Stan (4522) that positive attitudes are also outcomes of simulation-training. 
Table 2. Results of the Survey of the Perceptions of the Students in the Kumar et al. study. Learning - Perception Table

\begin{tabular}{|c|c|c|}
\hline Factors & Mean & Inference/Decision \\
\hline \multicolumn{3}{|l|}{ Change in Knowledge \& skills } \\
\hline $\begin{array}{l}\text { The skills/knowledge imparted } \\
\text { were applicable to my job. }\end{array}$ & 4.51 & $\begin{array}{l}\text { Favourable perception by the } \\
\text { respondents. }\end{array}$ \\
\hline $\begin{array}{l}\text { This course helped me do my job } \\
\text { better. }\end{array}$ & 4.42 & $\begin{array}{l}\text { Favourable perception by the } \\
\text { respondents. }\end{array}$ \\
\hline $\begin{array}{l}\text { The class room training helped } \\
\text { me to do my job better }\end{array}$ & 4.39 & $\begin{array}{l}\begin{array}{l}\text { Favourable perception by the } \\
\text { respondents. }\end{array} \\
\end{array}$ \\
\hline $\begin{array}{l}\text { The course training improved } \\
\text { my confidence levels. }\end{array}$ & 4.43 & $\begin{array}{l}\text { Favourable perception by the } \\
\text { respondents. }\end{array}$ \\
\hline $\begin{array}{l}\text { The simulator improved my } \\
\text { confidence levels. }\end{array}$ & 4.43 & $\begin{array}{l}\text { Favourable perception } \quad \text { by } \\
\text { respondents. }\end{array}$ \\
\hline
\end{tabular}

Following are two studies which explored the effects of training on the mental aspect of the trainees.Since training should result in mental stimulation, another study delved into the cognitive abilities - a reflection of the development of the knowledge and skills, as an effect of training. Tumala, Trumpeta, Evidente and Montano (523) showed the effect of simulation training on the cognitive styles of marine engineering students of a school in the Philippines. The one-group pretest- posttest design study revealed that in the measurement of spatial ability the impact of simulation training was high for both abstract and concrete learners as the average mean was at 90 for both groups. The difference in cognitive styles, at $p>0.05$ of the pre-test and post-test results did not indicate any significant results. Simulationtraining was concluded to be unselective of cognition styles. A summary of these results is shown in Table 3.

Table 3. Performance in the Simulator in the Tumala et al. study

\begin{tabular}{lll}
\hline Cognition & Mean & Description \\
\hline Abstract & 91 & High \\
Concrete & 88 & High \\
Mean Total & 90 & High \\
\hline
\end{tabular}

Though the study mentioned that in the group there were only 29 percent concrete learners and the greater majority were abstract learners, the deviations among the abstract learners appeared low. The pretest and post-test results determined the effects of simulation-training as a mean gain of 6.975 was obtained. This research indicated that the use of simulators may be beneficial regardless of the cognitive type of the learners. However, it may be argued that spatial ability may not have been solely attributed to the use of simulators. The research has not explored other factors that may have contribute to the spatial ability of the students.Research on the physiological effects indicating mental activity of simulation-training were conducted. The rationale for a specific study conducted by Teel, Sanders, Parrott, Wade, Gervais, Rovinski, Stone, Murai and Hayashi (2009) was to measure the extent of mental workload through measuring the heart variability as mental workload reflects the extent of ship handling decisions made while navigating in a channel. An excellent navigator is expected to be able to conduct effective passage planning and reduce, if not totally eliminate, the stress on the captain of the ship. Specifically, understanding complex traffic situations and making time decisions should be functions of the competent mariner's mental workload. Although the study involved professional skills of a captain, duty officer, and pilot, the insight gained was deemed useful to assist cadets in performing the same task. Heart variability or R-R interval was considered a useful indicator for assessing simulation training (Teel et al., 239). Figures 3 shows the instruments, a chest belt monitor, and wrist watch to measure R$\mathrm{R}$ interval. A Ship Bridge Simulator system of the Maine Maritime Academy (MMA) was used for this purpose. Figure 4 shows the simulator at MMA. With the use of the simulation system, the cadets should be able to produce a mental model of the situation. A quality of situational awareness, indicating calmness and the ability to take on the unanticipated, should be developed (Teel et al., 243). 


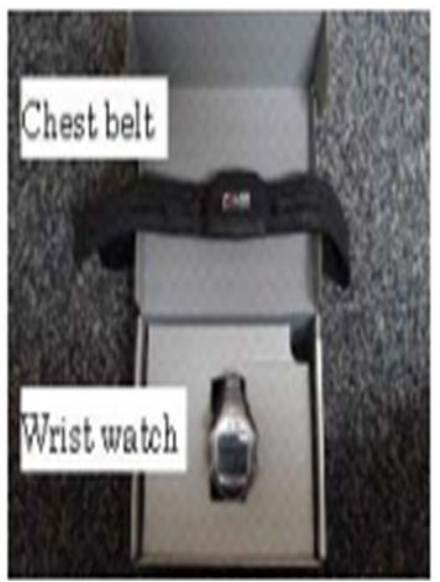

Figure 3. Instruments measuring the R-R interval in the Teel et al. experiment

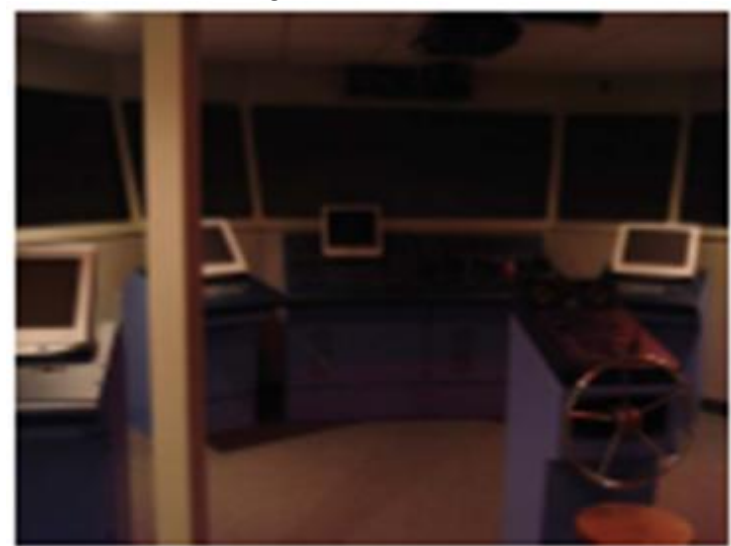

Figure 4. The simulator at MMA

Findings revealed that the Low Frequency/High Frequency (LF/HF) value rises in the mental workload during making decisions, aiming for ship navigation, for ship-handling at the professional level. Figure 5 shows a graph of the $\mathrm{LF} / \mathrm{HF}$ when one of the research participants was navigating a narrow channel. The peaks of the graph, as shown by peaks $\mathrm{C}$ and $\mathrm{D}$, were compared to the $\mathrm{LF} / \mathrm{HF}$ value during a less complex navigational situation, which indicated a rise in the mental activity. The researchers suggested that the $\mathrm{LF} / \mathrm{HF}$ value is a helpful indication of performance assessment. As commentary, measuring physiological responses in undertaking simulationtraining appears to be a sophisticated process in determining training response and may require additional investments in training equipment. However, this may capture information about the required level of cognitive activity to evaluate training.

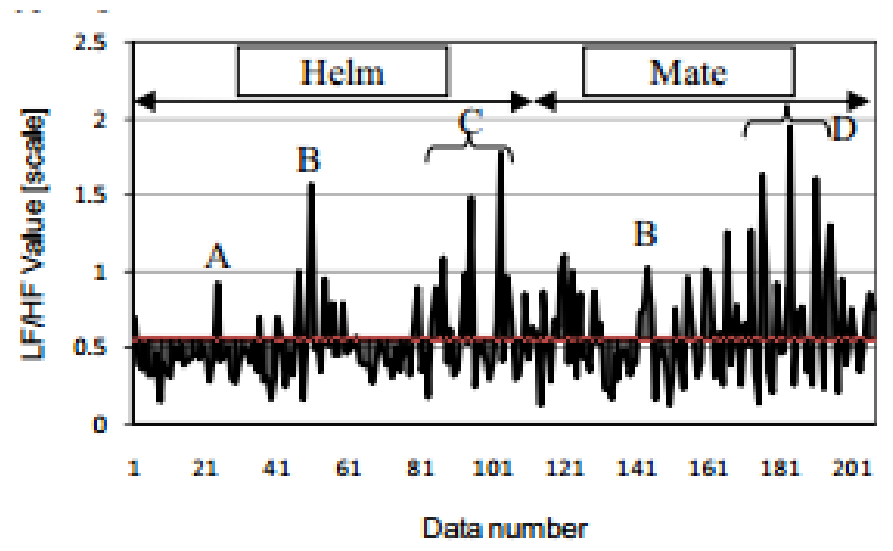

Figure 5. LF/HF value while navigating at a narrow channel 


\section{Marine Simulation systems}

Although there are various marine simulation systems available and there are many institutions which offer marine-simulation programs, the studies here were those available in accessible sources and those which partially touched on the effectiveness of training programs. Other literature merely covered the features and development of simulators which did not delve into the effects of training using them. Full Mission Marine Simulator (FMMS) is assessed to be valuable and effective in producing a qualified and competent seafarer (Xiuwen, Cui \& Yicheng, 1). Although this system is a fully immersive Visual Reality system used in marine training, it is expensive and requires high maintenance. This led researchers Xiuwen, Cui and Yicheng to develop a more efficient and low maintenance system Desktop Marine Teaching System (DMTS). In their study, another system, Web-based Marine Training Environment (WMTE) was used to determine the effects of enhancing marine education and training. The latter integrates web technology, high fidelity simulation, and e-learning tools for increased efficiency and training flexibility. The combination of the three systems resulted in a more consistent and effective medium for teaching knowledge and skills (Xiuwen, Cui \&
Yicheng, 1). The simulator blends other types of technology-based training methods such the internet and e-learning. Thus, the benefits of FMMS is compounded with the integration of these technologies. There is a possibility that learning outcomes may be intensified. However, this speculation needs to be evidenced by further research.

Another study described the training program used in Korea Maritime University (KMU). Here, Kim (81) described the Ship Handling Simulation (SHS) training which allowed the practice of ship handling to avoid accidents caused by the lack of ship handling skills. The simulation program's components and structures are illustrated in Figure 6. These include two bridges, $\mathrm{A}$ and $\mathrm{B}$, a computer image generator room, instructor control station, and debriefing room. The training objectives included the development of knowledge and skills in the following areas: normal navigation in a congested traffic area, prevention of collision, response to an emergency situation, restricted visibility channel and night navigation, ship maneuverability, anchoring, approaching and departing harbor, and berthing and unberthing. Appendix 2 presents an assessment guide for SHS to ensure the attainment of simulation-training objectives.

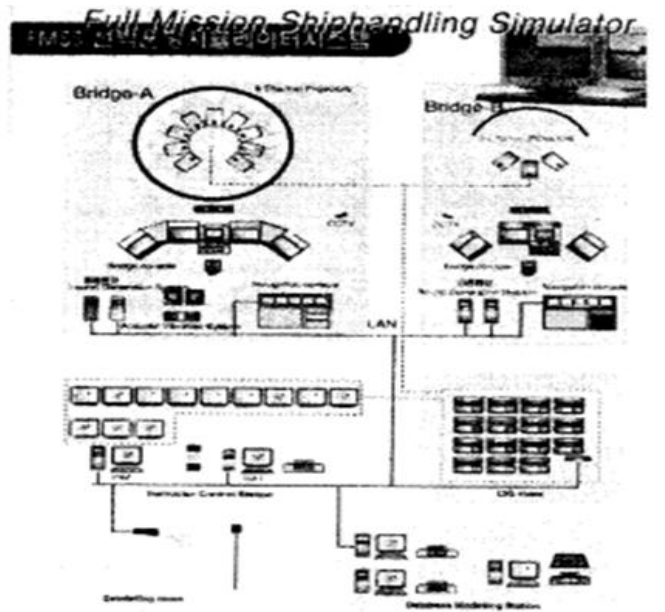

Figure 6. SHS program components and structures

KMU also has another simulator - the Bridge Resource Management (BRM) training which teaches proper and efficient management skills in bridge resources and reduction of errors. This program provides for training on human factors specifically on teamwork and leadership. A line of its training content can be viewed in Figure 7. Specific indicators of performance are formulated to assess the effectiveness of outcomes. Appendix 2 shows an assessment guide for BRM to ensure the attainment of simulation-training objectives. 


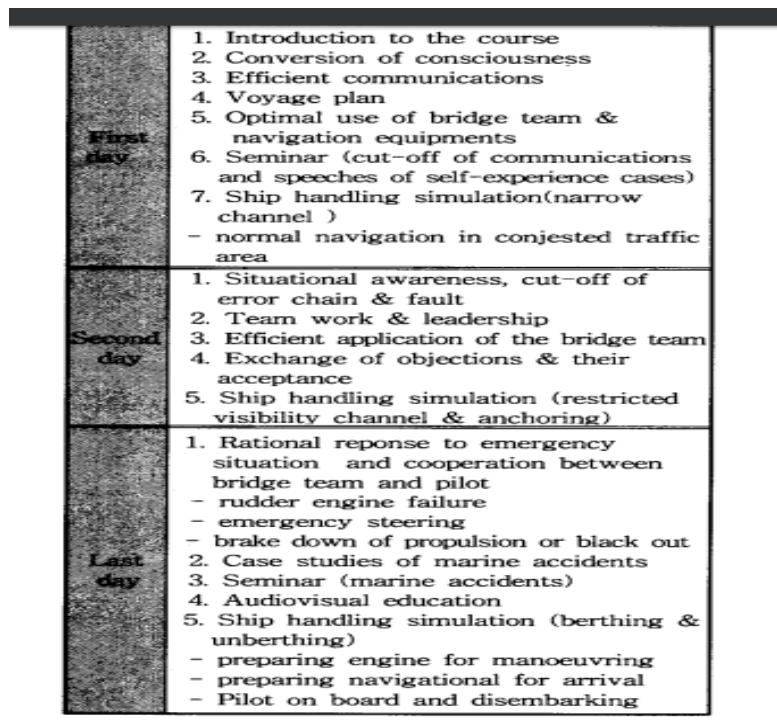

Figure 7.Three-day course of BRM at KMU

KMU indicated that simulator-training needs to be complemented by competent instructors. It is expected that as an educational institution, KMU would emphasize balance on the components of delivering education or training. It may be presumed that simulator-training is also moderated by the instructor. The instructor's competency would be another variable affecting the training outcomes. Another educational institution, Constanta Maritime University (CMU) in Romania, had documented the effects of simulation-training on their students. Since the course became compulsory in 2012 per STCW regulations, the passing rate for examinations on competency certificates has become higher. An increase in skill level was noted since which has led to the increased employment of Romanian cadets to the international maritime work force (Stan, 4525). Nonetheless, although employability may have indicated the ability to surpass the qualifications required for the position applied for, actual job performance still remains to be determined. Organizations still provide training and performance evaluations for the newly hired. Besides, accidents may logically be committed by less experienced personnel but there are accidents committed by supposedly more experienced crew.

\section{CONCLUSION}

Literature has shown that simulators are regarded beneficial tools for maritime training as training tools are developed to produce particular learning outcomes. Research in the service and training institutions consistently claimed the significant training results provided by simulation training. However, the learning outcomes appear to be intermediate outcomes which do not necessarily become conclusive to one of the main purposes of training, that is, to increase sea safety.
Intermediate outcomes were indicated in post-test results but do not seem to translate to expected actual performances or the on-the-job performances, considering the frequent concern on the number of accidents in various literature. The method of measuring performance through the difference of the pre-test and post-test may not strongly prove the correct performance at a future time nor performance in the actual scenario or onthe-job.

Moreover, research methodologies and implementations of the studies did not reflect strong validity criteria. Conclusions appear subject to logical arguments as issues in internal validity exist. First, compounding variables interfere with the direct effect of simulators to learning outcomes. Compounding variables included the competence of instructors and the mix of the level of experiences of classes.

\section{RECOMMENDATIONS}

In future research, the correlation of training performance and on-the-job performance must be established. Specifically, on-the-job performance must meet task outcomes such as safety or avoidance of accidents. The correlation may be established more definitely when the research design carefully considers the control of variables to isolate the effects of simulators on training effectiveness. Despite that training most often require instructors or facilitators, experimental procedures must control the instructors' effects. Similarly, the training conditions of the participants such as using equivalent groups should allow for increased validity in drawing conclusions regarding the effectiveness of simulator-training. 


\section{WORKS CITED}

[1]. Goldberg, Murray. Is simulator training worth it? E-News Magazine. 11 February 2013.www.maritimeprofessional.com/blo gs/post/is-simulator-training-worth-it13936. Accessed 24 January 2017.

[2]. Judson, Jen. Want to take simulated training where they fight. Defense News. 4 December2015.www.defensenews. com/s tory/defense/training-simulation/ 2015/ 12/04/ marines-want-to-take-simulatedtraining -where-it-fights/ 76772438/. Accessed 27 January 2017.

[3]. Kim, Chang-Je. Maritime education and training (MET) by ship handling simulator. Ocean Kristi. 2002. Volume 11. Number 4.81-89. ocean.kisti. re.kr/downfile/ volume/simul/ SMROBX/ 2002/v11n4/

SMROBX_2002_v11n4_81.pdf. Accessed 28 January 2017.

[4]. Kumar, Surender, Anand, Neeraj and Punia, DK. Simulator training and its effects on knowledge and skill levels of seafarers after training. Journal of Global Research Computer Science and Technology. Volume 3. Issue 3. 2015. 111.

[5]. Lewin, Peter. Training effectiveness in maritime transport. Buskerud and Vestfold University College. 2015.172.brage.bibsys.no/xmlui/bitstream/handle /11250/1558681/Lewin_Peter_2015_

Masteroppgave teksten.pdf? sequence=1. Accessed 28 January 2017.

[6]. Noe, Raymond. 'Simulations.' Employee Training and Development. $5^{\text {th }}$ edition. USA: McGraw-Hill. 2010. 270-271; 318320; 335 .

[7]. Noe, Raymond, Hollenbeck, John, Gerhart, Barry and Wright, Patrick. 'Simulations.' Human Resource Management. $5^{\text {th }}$ edition. USA: McGrawHill. 2006. 287-288.

[8]. Salman, Al-Kabie. The importance of using ship bridge simulation training to enhance the competency of masters and watch-officers: A case study of the Iraqi dredging fleet. The Maritime Commons: Digital Repository of the World. 2013.1119.commons.wmu.se/cgi/viewcontent. cgi?article $=1081 \&$ context=all_dissertation s. Accessed 29 January 2017.
[9]. Stan, Liviu Constantin. Simulation sechnology in educational process. Procedia - Social and Behavioral Sciences. 116. 2014. 4521-4525. ac.elscdn.com/S1877042814009951/1-s2.0-

S1877042

$814009951-$ main.pdf?_tid=9e0dbddc-e87a-11e6-ae9300000 aacb362\&acdnat $=1485952581$ ddfd2d7 ac2be 5 f0863423f721bd43106. Accessed 28 January 2017.

[10]. Teel, Sam, Sanders, Jim, Parrott, Daniel, Wade, Larry, Gervais, Timothy, Rovinski, Katherine, Stone, Laurie, Murai, Koji and Hayashi, Yuji. Evaluation of marine simulator training based on heart rate variability. Proceedings of the 2009 IEEE International Conference on Systems, Man, and Cybernetics. 2009. 239-244. ieeexplore.ieee.org/abstract/document/697 4132/. Accessed 28 January 2017.

[11]. Tumala, Brenda, Trompeta, Grace, Evidente, Luis and Montano, Ronnie. Impact of simulator training on cognition of marine engine students. 2008. John B. Lacson College IMLA. 523-529. web.deu.edu.tr/maritime/imla2008/Papers/ 56.pdf. Accessed 28 January 2017.

[12]. United States Government Accountability Office (US GAO). Better performance and cost data needed to more fully assess simulation-based efforts.Army and Marine Corps Training Report to Congressional Committees. August 2013.5 ${ }^{\text {th }}$ World Conference on Educational Sciences. www.gao.gov/assets/660/657115.pdf. Accessed 27 January 2017.

[13]. Wang , Peng, Cheng, Xiangxin, Ma, Oiang, Song, Xiufu, Liu, Xinjian and Wang, Lianhai. "Influence of marine engine simulator training to marine engineer's competence", Proc. SPIE 8349, Fourth International Conference on Machine Vision (ICMV 2011): Machine Vision, Image Processing, and Pattern Analysis, 834924 (January 11, 2012); doi:10.1117/12.920075

[14]. Xiuwen, Liu, Cui, Xie, and Yicheng, Jin. Multi-level virtual reality system for marine education and training. Education, Technology, and Computer Science. 2009. ETCS. First International Workshop.//ieeexplore.ieee.org/abstract/do cument/4959211/. Accessed 28 January 2017. 
Appendix 1

Advanced Instrumentation Pre-test and Post-test results

\begin{tabular}{|c|c|c|c|c|c|c|c|c|c|}
\hline Nerforsance Neasure & nealue & $\begin{array}{l}\text { Aretralining } \\
\text { Sevolard } \\
\text { Sevitation }\end{array}$ & Coment & wotive & $\begin{array}{l}\text { Nosteralining } \\
\text { Standere } \\
\text { Deviation }\end{array}$ & Coment & $t^{t-7 e}$ & $s t, 0$ & $\begin{array}{l}\text { Einosinel } \\
\text { lest } \\
0 \leq\end{array}$ \\
\hline 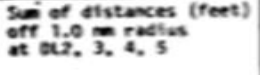 & 734.0 & 359.4 & $\rightarrow-9$ & 384.8 & 355.6 & $m * 10$ & 2.269 & $0.025^{*}$ & $\begin{array}{c}\text { Mann-waittreg, } \\
a<.01\end{array}$ \\
\hline 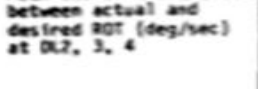 & 0.22 & 0.09 & $=10$ & 0.14 & 0.06 & $\infty=10$ & 4.003 & $0.001^{*}$ & \\
\hline Nmeer of ruater sorters & 11.6 & 7.2 & 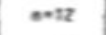 & 22.9 & 6.5 & $\infty 12$ & 0.464 & s.s. & \\
\hline Never of course erters & 2.25 & 10 & -12 & 1.13 & 1.11 & $=12$ & 1.702 & 0.100 & \\
\hline 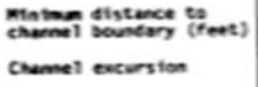 & 163.0 & mos & $\begin{array}{c}n+12 \\
4,12 \text { res }\end{array}$ & 238.5 & 85.6 & $\begin{array}{c}n+12 \\
1 / 22 \text { yes }\end{array}$ & 2.158 & $.025^{\circ}$ & n.s. \\
\hline
\end{tabular}

P.5.:-tafled test

\section{Appendix 2}

Emergency Ship Handling Performance Results

\begin{tabular}{|c|c|c|c|c|c|c|c|c|c|}
\hline Performance Measure & $\begin{array}{l}\text { Mean } \\
\text { value }\end{array}$ & $\begin{array}{l}\text { Pretraining } \\
\text { Standard } \\
\text { Deviation }\end{array}$ & Coment & $\begin{array}{l}\text { Nean } \\
\text { value }\end{array}$ & $\begin{array}{l}\text { Posttraining } \\
\text { Standard } \\
\text { Deviation }\end{array}$ & Comnent & $t^{t-T e s}$ & st $p<$ & $\begin{array}{c}\text { Binominal } \\
\text { Test } \\
\text { pe }\end{array}$ \\
\hline Channel excurstion & & & $6 / 12$ yes & & & $0 / 12$ yes & & & 0.02 \\
\hline $\begin{array}{l}\text { Miniane distance to } \\
\text { channel boundary (feet) }\end{array}$ & 75.0 & 105.5 & $n=12$ & 129.2 & 83.8 & $n=12$ & 1.390 & $0.10^{*}$ & \\
\hline $\begin{array}{l}\text { Course Correction (deg) } \\
\text { ot } 4 \text { kts }\end{array}$ & 16.7 & 11.4 & $n=12$ & 10.7 & 2.7 & $n=12$ & N.A. & & \\
\hline $\begin{array}{l}\text { Dotior of rodoler orders } \\
\text { prionge } \\
\text { changes ing }\end{array}$ & 7.0 & 4.4 & $n=12$ & 4.4 & 2.7 & $n=12$ & & 1.745 & $.05^{*}$ \\
\hline $\begin{array}{l}\text { Poter of course orders } \\
\text { prior to } 300 \text { head ing } \\
\text { change }\end{array}$ & 1.9 & 2.2 & $n=12$ & 4.3 & 4.1 & $n=12$ & & 1.787 & $.05^{*}$ \\
\hline $\begin{array}{l}\text { Nuber of engine orders } \\
\text { prior to } 300 \text { heasing } \\
\text { change }\end{array}$ & 6.2 & 2.7 & $n=12$ & 3.2 & 3.0 & $n=12$ & & 2.575 & 0.02 \\
\hline
\end{tabular}

M.s.:- Woiled test

N.A.: Not appropriate due to unequal variances

\section{Appendix 3}

Assessment Guide for SHS at KMU

\begin{tabular}{|c|c|}
\hline Sar & $\begin{array}{l}\text { 1. Head on situation } \\
\text { 2. Crossing situation } \\
\text { 3. Overtaking situation } \\
\text { 4. TSS } \\
\text { 5. Restricted visibility } \\
\text { 6. Nav-aids identification }\end{array}$ \\
\hline $\begin{array}{c}\text { Maneuyering } \\
\text { skill }\end{array}$ & $\begin{array}{l}\text { 1. Use of } \mathrm{M} / \mathrm{E} \\
\text { 2. Application of wheel over point } \\
\text { 3. Position confirmation } \\
\text { 4. Application of parallel indexing } \\
\text { 5. Emergency response Training } \\
\text { for collision avoidance }\end{array}$ \\
\hline $\begin{array}{c}\text { Voyage } \\
\text { plan }\end{array}$ & $\begin{array}{l}\text { 1. Suggestion of an opinion } \\
\text { 2. Collection of information \& } \\
\text { its application } \\
\text { 3. Application of safety margin } \\
\text { 4. Application of emergency plan }\end{array}$ \\
\hline Commucation & $\begin{array}{l}\text { 1. Inter- bridge team } \\
\text { 2. Ship to shore } \\
\text { 3. Ship to ship }\end{array}$ \\
\hline
\end{tabular}


Appendix 4

Assessment Guide for BRM at KMU

\begin{tabular}{|l|l|}
\hline 1. Application of CORLEG & $\begin{array}{l}\text { 2. Proper speed } \\
\text { 3. Proper LEE-WAY against } \\
\text { external force } \\
\text { 4. Use of M/E \& Steering } \\
\text { Control of tug boat }\end{array}$ \\
\hline 1. Situation awareness \\
2. Positive mind
\end{tabular}

Ins. Rashed AlshahinไHTNI 